Nonlin. Processes Geophys., 20, 921-933, 2013

www.nonlin-processes-geophys.net/20/921/2013/

doi:10.5194/npg-20-921-2013

(c) Author(s) 2013. CC Attribution 3.0 License.

(c) (i)

\title{
Lagrangian transport in a microtidal coastal area: the Bay of Palma, island of Mallorca, Spain
}

\author{
I. Hernández-Carrasco ${ }^{1}$, C. López ${ }^{1}$, A. Orfila ${ }^{2}$, and E. Hernández-García ${ }^{1}$ \\ ${ }^{1}$ IFISC, Instituto de Física Interdisciplinar y Sistemas Complejos (CSIC-UIB), 07122 Palma de Mallorca, Spain \\ ${ }^{2}$ IMEDEA, Instituto Mediterráneo de Estudios Avanzados (CSIC-UIB), 07190 Esporles, Spain
}

Correspondence to: I. Hernández-Carrasco (ismael@ifisc.uib-csic.es)

Received: 12 April 2013 - Revised: 24 September 2013 - Accepted: 25 September 2013 - Published: 31 October 2013

\begin{abstract}
Coastal transport in the Bay of Palma, a small region in the island of Mallorca, Spain, is characterized in terms of Lagrangian descriptors. The data sets used for this study are the output for two months (one in autumn and one in summer) of a high resolution numerical model, ROMS (Regional Ocean Model System), forced atmospherically and with a spatial resolution of $300 \mathrm{~m}$. The two months were selected because of their different wind regime, which is the main driver of the sea dynamics in this area. Finitesize Lyapunov exponents (FSLEs) were used to locate semipersistent Lagrangian coherent structures (LCS) and to understand the different flow regimes in the bay. The different wind directions and regularity in the two months have a clear impact on the surface bay dynamics, whereas only topographic features appear clearly in the bottom structures. The fluid interchange between the bay and the open ocean was studied by computing particle trajectories and residence time (RT) maps. The escape rate of particles out of the bay is qualitatively different, with a $32 \%$ greater escape rate of particles to the ocean in October than in July, owing to the different geometric characteristics of the flow. We show that LCSs separate regions with different transport properties by displaying spatial distributions of residence times on synoptic Lagrangian maps together with the location of the LCSs. Correlations between the time-dependent behavior of FSLE and RT are also investigated, showing a negative dependence when the stirring characterized by FSLE values moves particles in the direction of escape.
\end{abstract}

\section{Introduction}

The study of transport and mixing in coastal flows is of major interest because of their economic and ecological importance. Due to the particularities that they present, like influence of complex topography, coastline shape and the direct driving at the surface by highly variable wind forcing, coastal flow dynamics remains still poorly understood.

Recently, coastal observations and modeling efforts in different regions have been addressed from the Lagrangian point of view: Lekien et al. (2005) showed that Lagrangian coherent structures (LCSs) computed from velocity fields obtained from HF (high frequency) radar measurements can be used to predict pollutant dispersion in the coast of Florida; Gildor et al. (2009) and Shadden et al. (2009) detected LCSs with HF radar data in the Gulf of Eliat, Israel, and in Monterey Bay, respectively. Haza et al. (2010) studied smallscale properties of dispersion measurements obtained from HF radar data in the Gulf of La Spezia, Italy. Also Nencioli et al. (2011) have detected LSCs in a coastal region with a Lyapunov method based on in situ observations. Besides radar measurements, LCSs obtained from velocity data of high resolution numerical models have been used to analyze the effect of the waves on LCS in the Bay of Palma, Spain (Galan et al., 2012), to study the transport in the tidal flow of Ria de Vigo, Spain (Huhn et al., 2012), or to study the water quality of a very small coastal region, the Hobie Beach, USA (Fiorentino et al., 2012). Also, data from drifters released in the Santa Barbara Channel were used by Ohlmann et al. (2012) to characterize relative dispersion, very useful to improve Lagrangian stochastic models. The application of Lagrangian techniques to study the dynamics in a shallow lake (small closed basin) has been performed in PattantyúsÁbrahám et al. (2008). 
Palma is the largest city in the Balearic Islands. Because of human activities, in particular recreational ones, the water quality in the Bay of Palma represents a large economic value. A proper analysis of transport can be useful to understand the fluid dynamics in the bay and therefore help protect the coastal water. Previous studies performed in the Bay of Palma used Eulerian techniques to understand the coastal dynamics (Jordi et al., 2009, 2011). In this work we study some transport properties in the Bay of Palma using Lagrangian techniques developed from dynamical systems theory. Computing both LCSs and residence times the Bay of Palma can be sorted in regions of different properties, for example, having more or less connectivity with the open ocean. These kinds of studies have demonstrated to be useful to identify pollution pathways or conditions for red tides (Lekien et al., 2005; Fiorentino et al., 2012). The bay is a semi-enclosed basin located in the southwest of the island of Mallorca (western Mediterranean Sea), whose coastal flow is mainly induced by wind (Jordi et al., 2009, 2011). Forcing by tides is almost negligible with a tidal amplitude of less than $0.25 \mathrm{~m}$. This makes the dynamics here different form other locations (e.g., Shadden et al., 2009; Huhn et al., 2012) where tides are dominant, and therefore provides the opportunity to test the performance of dynamical systems tools in this situation in which forcing only acts directly on the sea surface, and in which there are rather different forcing regimes depending on the season. The Lagrangian diagnosis will be obtained from velocity data of a realistic numerical model at high resolution, which resolves spatial scales of a few hundred of meters. We investigate the surface horizontal transport during two months corresponding to different seasons (autumn and summer), and therefore to different wind conditions, in order to highlight the effect of the wind on transport. In the case of July we also study the deepest bottom layer. We compute the barriers and avenues to transport (LCS) from lines of high values of finite-size Lyapunov exponents (FSLE). We also present calculations of residence times and show synoptic Lagrangian maps (SLM) of these times (Lipphardt et al., 2006), which will allow us a detailed visualization of the interchange of fluid particles between the bay and the open sea. The relationship between LCSs and areas of different residence times will be analyzed.

The organization of this paper is as follows. The data set used in the computations and the area of study is described in Sect. 2. Section 3 presents a brief overview of the Lagrangian tools that are used. Before presenting the Lagrangian results, we show in Sect. 4 a short summary of Eulerian results by studying the velocities in the bay. We present in Sect. 5 a characterization of stirring in the Bay of Palma in terms of FSLE and residence times. Using the definition of LCS given in Sect. 3, Lagrangian barriers are identified in the domain of interest. We compute escape rates and residence times of fluid particles to describe the transport relation between the bay and the open ocean. We provide possible mechanisms to explain differences in the residences times and

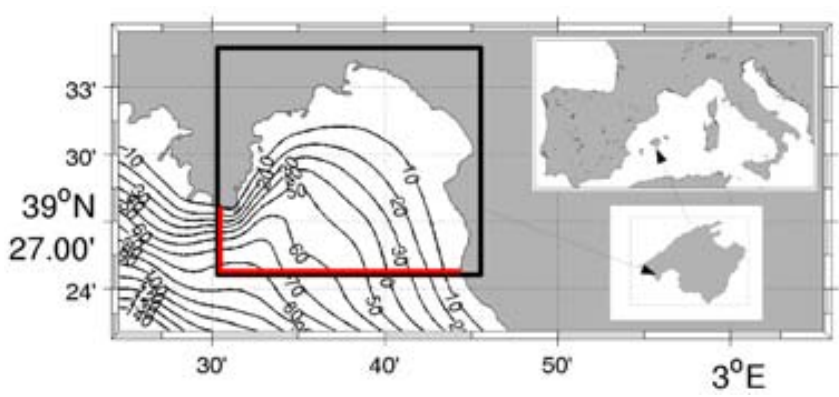

Fig. 1. Bathymetry contours (in meters) of the model domain. The black box indicates the Bay of Palma and the inset graphics give the geographical location of Mallorca Island in the western Mediterranean Sea.

FSLE between different seasonal months. Finally, we summarize the main results in Sect. 6 .

\section{Data and characteristics of the study region}

\subsection{Area of study}

The island of Mallorca (Fig. 1) is part of the Balearic Islands archipelago and is located in the center of the western Mediterranean (between $39^{\circ}$ and $40^{\circ} \mathrm{N}$ and $2.50^{\circ}$ and $3.50^{\circ} \mathrm{E}$ ). The Bay of Palma is a nearly semi-circular and semi-enclosed basin located in the southwest coast of Mallorca and it can reach depths of more than $60 \mathrm{~m}$. The Bay of Palma is defined as the water mass inside the square in Fig. 1, consisting of a northern limit at $39^{\circ} 34^{\prime} \mathrm{N}$, a southern limit at $39^{\circ} 24^{\prime} \mathrm{N}$, and $2^{\circ} 30^{\prime} \mathrm{E}$ and $2^{\circ} 45^{\prime} \mathrm{E}$ as the western and eastern limits, respectively. The open boundary to the sea is in the southern part and it is $20 \mathrm{~km}$ wide.

The size of the bay is smaller than the Rossby radius of deformation at these latitudes, and the main circulation is determined by the bathymetry at the bottom layer and by local and remote winds at the surface layer. In particular, the studies by Jordi et al. $(2009,2011)$ have shown that the major forcing mechanisms come from wind-induced island trapped waves (ITW) propagating at an island scale and by locally windinduced mass balance. The intense ITW can produce new instabilities that can generate coastal gyres at submesoscale (see Jordi et al., 2011). During summer there are persistent sea breeze conditions. In July and August, the weather is often almost identical from one day to the next. In the vicinity of the Bay and along the southern coast of Mallorca the breeze blows from the southwest. Several studies (Ramis and Alonso, 1988; Ramis and Romero, 1995), have pointed out that the meteorological conditions of Mallorca (intense solar radiation, clear skies, soil water deficit, dryness, weak surface pressure gradients, etc.) favor the development of the sea breeze, often from April to October and almost every day during July and August. Winds in autumn, and particularly in 
late September and October are more irregular, with episodes of strong storm activity (Tudurí and Ramis, 1997).

\subsection{Data}

The velocity data sets were obtained from the numerical model ROMS (Regional Ocean Model System). ROMS is a free surface, hydrostatic, primitive equation ocean model. The model uses a stretched, generalized nonlinear coordinate system to follow bottom topography in the vertical, and orthogonal curvilinear coordinates in the horizontal (Song and Haidvogel, 1994; Haidvogel et al., 2000). At each grid point, horizontal resolution $\Delta_{0}$ is the same in both the longitudinal, $\phi$, and latitudinal, $\theta$, directions.

We run the simulation with a resolution of $\Delta_{0}=0.0027^{\circ}$ ( $\sim 300 \mathrm{~m}, \mathrm{ROMS} 300)$, which is itself nested into a larger and coarser grid with $\Delta_{0}=1 / 74^{\circ}(\sim 1500 \mathrm{~m})$. Boundary conditions for the coarser domain were taken from daily outputs of the Mediterranean Forecasting System (Dobricic et al., 2007; Oddo et al., 2009). The ROMS300 domain covers $39^{\circ} 12^{\prime}-$ $39^{\circ} 36^{\prime} \mathrm{N}$ (latitude), and $2^{\circ} 24^{\prime}-3^{\circ} 6^{\prime} \mathrm{E}$ (longitude). The total number of grid nodes is $260 \times 148$. Vertical resolution is variable with 10 layers in total. All domains were forced using realistic winds provided by the PSU/NCAR mesoscale model MM5. The initial vertical structure of temperature and salinity was obtained from the Levitus database (Locarnini et al., 2006; Antonov et al., 2006).

We will manage velocity data from the surface layer and the bottom layer for the grid of $\Delta_{0} \approx 300 \mathrm{~m}$. This domain allows us to analyze the fluid interchange between the bay and the open ocean, using a high resolution velocity field. Only horizontal velocities are considered, so that vertical displacements are neglected in the surface layer, and particles in the bottom remain in the bottom layer. This is justified by the small integration times we will use. Nevertheless, close to the coast they can have an impact that will be the subject of future work. The output of the model was compared with data from drifters (see Galan et al., 2012) and a reasonable agreement was found, although it improved when adding the influence of wave intensity. Thus the present study should be considered as a simplified baseline case against which to compare the future consideration of the full 3-D dynamics, or the influence of small-scale process such as waves (Galan et al., 2012). We will study two different intervals of time corresponding to two different wind regimes: one starting on 5 October 2008 and finishing on 29 October 2008; and the other extending from 1 July 2009 until 26 July 2009. Temporal resolutions are 15 and $10 \mathrm{~min}$ for October and July, respectively, resulting in a total of 2375 snapshots of the velocity field for October, and 3744 for July.

\section{Methodology}

\subsection{LCSs and particle dispersion from FSLE}

Our methodology is based on the Lagrangian analysis of marine flows. In the Lagrangian view, particles are advected by the flow and their horizontal motion (neglecting motions between model layers) is governed by the differential equations

$\frac{\mathrm{d} x}{\mathrm{~d} t}=v_{x}(x, y, t)$,
$\frac{\mathrm{d} y}{\mathrm{~d} t}=v_{y}(x, y, t)$,

where $(x(t), y(t))$ are the west-east and the south-north coordinates of the trajectories and $\left(v_{x}, v_{y}\right)$ are the eastwards and northwards components of the velocity. Because of the small sizes involved, we will use a Cartesian coordinate system.

LCSs (Haller and Yuan, 2000; d'Ovidio et al., 2004; Shadden et al., 2005) are roughly defined as the material lines organizing the transport in the flow. They are the analogs, for time-dependent flows of the unstable and stable manifolds of hyperbolic fixed points. Among other approaches (Mancho et al., 2006; Mendoza and Mancho, 2010; Mezić et al., 2010; Rypina et al., 2011; Haller and Beron-Vera, 2012), ridges of the local Lyapunov exponents provide a convenient tool to locate them. In our case, we use the so-called FSLEs, which are the adaptation of the asymptotic classical Lyapunov exponent to finite spatial scales (Aurell et al., 1997; Boffetta et al., 2001). FSLEs are a local measure of particle dispersion and thus of stirring and mixing, as a function of the spatial resolution, serving to isolate the different regimes corresponding to different length scales of the oceanic flows, very useful in coastal systems (Cencini et al., 2010). In fact the first applications of the FSLE technique in oceanography were for closed or semi-closed basins (Buffoni et al., 1996, 1997).

For two particles of fluid, one of them located at $\boldsymbol{x}$, the FSLE at time $t_{0}$ and at the spatial point $\boldsymbol{x}$ is given by the formula

$\lambda\left(\boldsymbol{x}, t_{0}, \delta_{0}, \delta_{\mathrm{f}}\right)=\frac{1}{|\tau|} \ln \frac{\delta_{\mathrm{f}}}{\delta_{0}}$,

where $\delta_{0}$ is the initial distance of the two given particles, and $\delta_{\mathrm{f}}$ is their final distance. Thus, to compute the FSLEs we need to calculate the minimal time, $\tau$, needed for the two particles initially separated $\delta_{0}$, to get a final distance $\delta_{\mathrm{f}}$ (in this way the FSLE represents the inverse timescale for mixing up fluid parcels between length scales $\delta_{0}$ and $\delta_{\mathrm{f}}$ ). To obtain this time we need to know the trajectories of the particles (from Eqs. 1 and 2) which give the Lagrangian character to this quantity. The FSLEs are computed for the points $x$ of a square lattice with lattice spacing coincident with the initial separation of fluid particles $\delta_{0}$. We can obtain a good estimation of the minimal $\tau$ at each site by selecting the trajectory that diverges first among the four trajectories starting next to the given site in the grid of initial conditions. 
Numerically, we integrate the equations of motion using a standard, fourth-order Runge-Kutta scheme, with an integration time step corresponding to the time resolution of the velocity data: $\mathrm{d} t=15 \mathrm{~min}$ in October and $\mathrm{d} t=10 \mathrm{~min}$ in July. We have checked in selected trajectories that using in July the same time step $\mathrm{d} t=15$ as in October does not alter the trajectories. Since velocity information is provided just in a discrete space-time grid, spatiotemporal interpolation of the velocity data is achieved by bilinear interpolation. For the spatial scales that define FSLEs, we take $\delta_{\mathrm{f}}=0.1^{\circ}$, i.e., final separations of about $10 \mathrm{~km}$, because of the size of the bay. On the other side, we take $\delta_{0}$ equal to $75 \mathrm{~m}$, four times smaller than the resolution of the velocity field, $\Delta_{0}=300 \mathrm{~m}$. Since we are interested only in fast timescales, our integrations are restricted to 5 days. Locations for which the final separation at the end of this period has not reached the prescribed $\delta_{\mathrm{f}}=10 \mathrm{~km}$ (or for which particles have been trapped by land) are assigned a value $\lambda=0$.

FSLEs can be computed from trajectory integration backwards and forward in time. Their highest values as a function of the initial location, $\boldsymbol{x}$, organize in filamental structures approximating relevant manifolds: ridges in the spatial distribution of backward (forward) FSLEs identify regions of local maximum compression (separation), approximating attracting (repelling) material lines or unstable (stable) manifolds of hyperbolic trajectories, which can be identified with the LCSs (Haller and Yuan, 2000; d'Ovidio et al., 2004; Shadden et al., 2005; Tew Kai et al., 2009; Hernández-Carrasco et al., 2011), and characterize the flow from the Lagrangian point of view (Joseph and Legras, 2002; Koh and Legras, 2002). Attracting LCSs associated to backward integration (the unstable manifolds) have a direct physical interpretation (Joseph and Legras, 2002; d'Ovidio et al., 2004, 2009). Tracers (chlorophyll, temperature, etc.) spread along these attracting LCSs, thus creating their typical filamental structure (Tél and Gruiz, 2006; Lehan et al., 2007; Tew Kai et al., 2009; Calil and Richards, 2010). When not stated explicitly, by FSLE we will mean the backwards FSLE values. In addition to locating spatial structures, time averages of FSLE give an indication of the intensity of stirring in given areas, which we analyze in Sect. 5.1.

We close this section by noting that the relationship between LCSs and Lyapunov exponents is based on heuristic arguments, which may not be correct in some cases (see for example Haller, 2011). We identify as possible LCSs only the locations having the largest values of FSLE, which align in linear structures. In this way we effectively select only the highest FSLE ridges, which are more likely to organize the flow. Even in this case, it is possible that the FSLE technique identifies regions of high shear that are not hyperbolic and may lack some of the properties of bona fide LCSs. Thus, direct inspection of particle trajectories and comparison with complementary techniques would be needed to confirm the validity of the FSLE approach in this situation. One of such complementary techniques are the residence time maps that we present in the following section.

\subsection{Escape and residence times}

Another characteristic timescale for transport processes in open flows is the so-called escape rate (Lai and Tel, 2011). This quantity measures how quickly particle trajectories escape from a domain. If we initiate $N(0)$ particles in a flow, we can measure how the trajectories escape the preselected region. In the case in which the decay in the number of particles remaining in the region up to time $t, N(t)$, decays exponentially with time, $N(t) / N(0) \sim e^{-\kappa t}$, there is a welldefined escape time defined as the inverse of the escape rate $\kappa: \tau_{\mathrm{e}}=1 / \kappa$. For the range of times explored in our work, we will see that the particle escape is close to exponential and that we can estimate the value of $\tau_{\mathrm{e}}$.

$\tau_{\mathrm{e}}$ is a global quantity associated to the whole basin. A more detailed description of the transport processes can be obtained by other suitable Lagrangian quantities such as residence times (Buffoni et al., 1996, 1997; Falco et al., 2000; Orfila et al., 2005). The particle residence time (RT) is defined as the interval of time that a fluid particle remains in a region before crossing a particular boundary. For each fluid particle inside the bay at an initial time, we need to compute two times: the forward exit time, $t_{\mathrm{f}}$, computed as the time needed for a particle to cross the line delimiting the bay, taking the forward-in-time dynamics; and the backward exit time, $t_{\mathrm{b}}$, the same but in the backward-in-time dynamics. The residence time is defined as $\mathrm{RT}=t_{\mathrm{f}}+t_{\mathrm{b}}$. RTs can be displayed in plots named Lagrangian synoptic maps (Lipphardt et al., 2006), in which the residence time of each fluid particle is referenced to its initial position on the grid.

\section{Preliminary Eulerian description}

A first approach to the transport process in the bay can be a description from the Eulerian point of view, by studying averages of the velocity field. To do this we consider separately the meridional $v_{y}$ and zonal $v_{x}$ components of the surface flow, and we analyze the time evolution of their spatial averages.

Figure $2 \mathrm{a}$ and $\mathrm{b}$ show the time series of data taken every $15 \mathrm{~min}$ in October and $10 \mathrm{~min}$ in July (black lines), and daily average time series (red lines) of $v_{x}$ and $v_{y}$ for October and July, respectively. The impact of the more variable and stormy weather in October is clear in the high frequency variability of the time series. During the two months both components of the flow present daily variability related to the presence of land and sea breezes. In July the zonal fluctuations are much more noticeable and regular than the meridional ones, being $\left\langle v_{y}\right\rangle$ very small. We have computed the power spectra for both months (see Fig. 3). In October, in addition to higher power at high frequencies, there are also stronger 


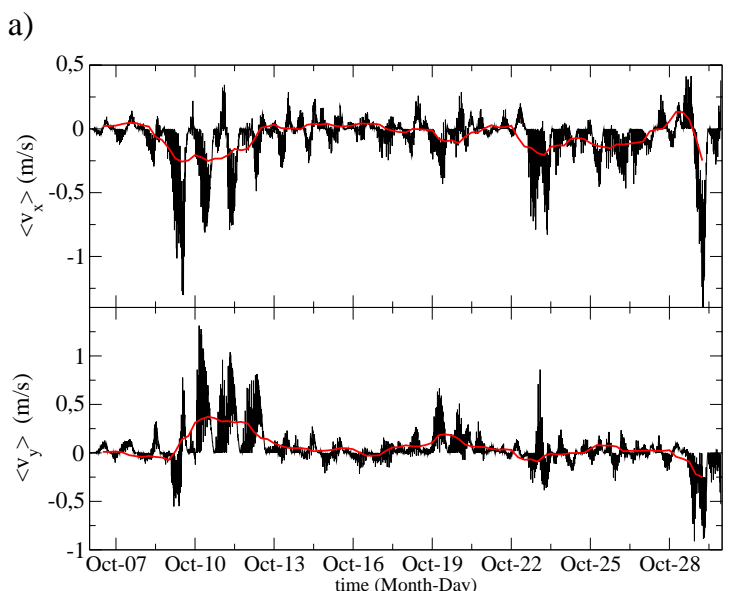

b)

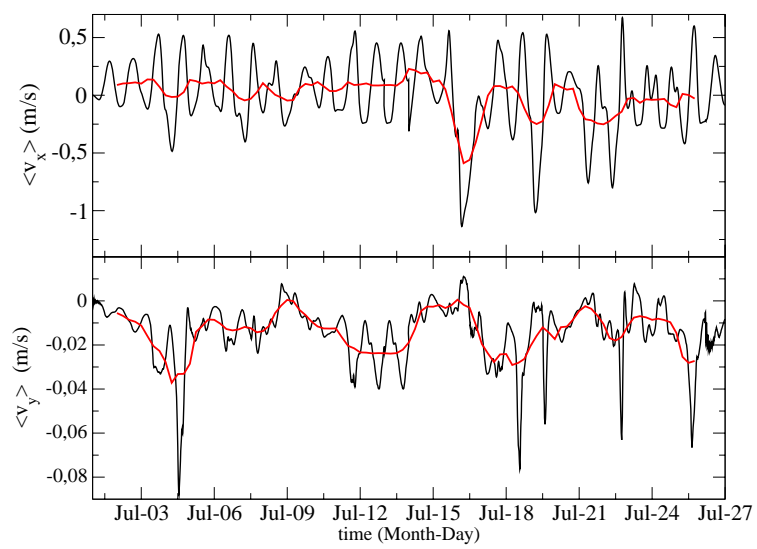

Fig. 2. (a) Complete time series throughout October of the zonal (top panel) and meridional (bottom panel) of the spatial average of the surface velocity field (black line). The red line is a running daily average. (b) Same as (a) but for July.

low-frequency fluctuations. From such features in their spectra of ADCP-derived velocities Jordi et al. (2011) identified wind-induced island trapped waves as the main source of variability in the bay dynamics, in addition to the local wind (essentially sea breeze). In contrast, the dominant role of sea breeze in July is seen as the very strong dominance of the daily frequency peak at the July zonal spectrum.

Comparing the velocity components of both months we observe quantitative differences. The values of $v_{y}$ in the case of October range from -1.0 to $1.5 \mathrm{~m} \mathrm{~s}^{-1}$ (bottom panel in Fig. 2a), while in the case of July, $v_{y}$ is two orders of magnitude smaller, ranging from -0.1 to $0.02 \mathrm{~m} \mathrm{~s}^{-1}$ (bottom panel in Fig. 2b). On other hand, $v_{x}$ are similar during October and July. In October, $v_{x}$ ranges from -1.5 to $0.5 \mathrm{~m} \mathrm{~s}^{-1}$ (top panel in Fig. 2a), the same order of magnitude than the meridional velocity, resulting in circular motions (clockwise along the bay). In July the situation is significantly different. The zonal velocity ranges from -1.5 to $0.7 \mathrm{~m} \mathrm{~s}^{-1}$ (top panel in Fig. 2b), much larger than
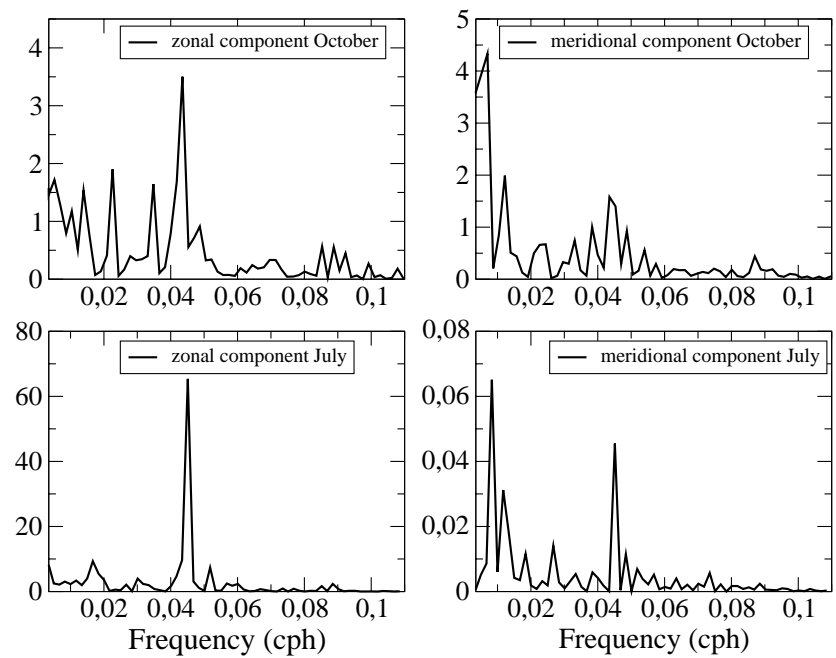

Fig. 3. Spectra for the zonal (left panels) and meridional components (right panels) of the surface velocity field $\left(\mathrm{m}^{2} \mathrm{~s}^{-1}\right)$ in October (top) and July (bottom)

the meridional velocity, resulting in a flow consisting on oscillations along the zonal direction. In October the mean values (and the standard deviations given in parenthesis) of the time series are $\left\langle v_{x}\right\rangle=-0.0704 \quad(0.1897) \mathrm{m} \mathrm{s}^{-1}$ and $\left\langle v_{y}\right\rangle=0.0440 \quad(0.1982) \mathrm{m} \mathrm{s}^{-1}$. In July we have $\left\langle v_{x}>=0.0013 \quad(0.3052) \mathrm{m} \mathrm{s}^{-1}\right.$ and $\left\langle v_{y}\right\rangle=$ $-0.0140(0.0134) \mathrm{m} \mathrm{s}^{-1}$. The large standard deviation in the zonal velocity in July is an indicator of the large (breeze induced) daily fluctuations in this month, but restricted to a single direction of motion.

\section{Lagrangian results}

\subsection{Average characterization of stirring}

We now describe our Lagrangian results. First we compute the temporal average (over the months of October and July) of the FSLEs for the surface layer, and for July in the bottom layer. This calculation helps us to unveil areas of different stirring and the differences between layers and months.

The surface computations for the different seasonal months, October and July (Fig. 4a, b) show different values and spatial distributions of stirring. We use the same color bar to compare the stirring in both months. The Bay of Palma appears to be an area with important activity. The average FSLE field looks more homogeneous in July than in October. During October filamental structures of high values of FSLE are accumulated over the northeast side of the bay, forming a linear structure running from north to southeast, which comes from similar structures in the instantaneous (non-averaged) fields that can act as barriers, therefore dividing the bay in two flow regions of qualitatively different dynamics. The difference in wind regularity and 
a)

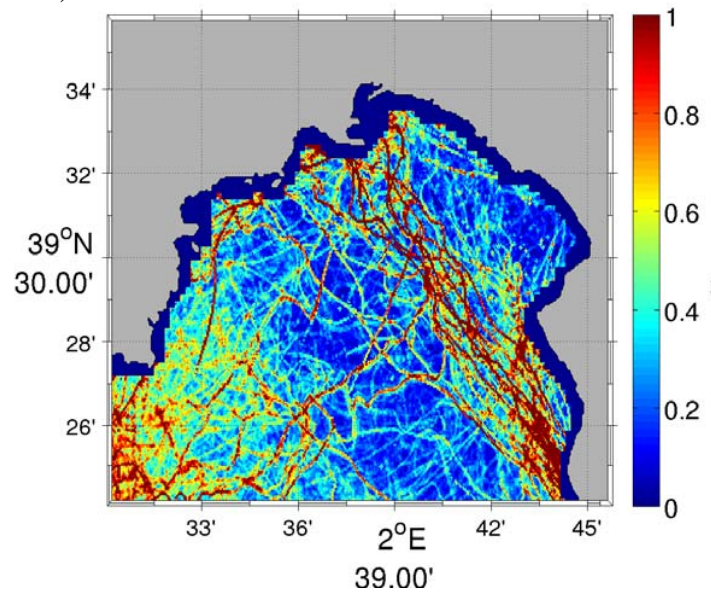

b)

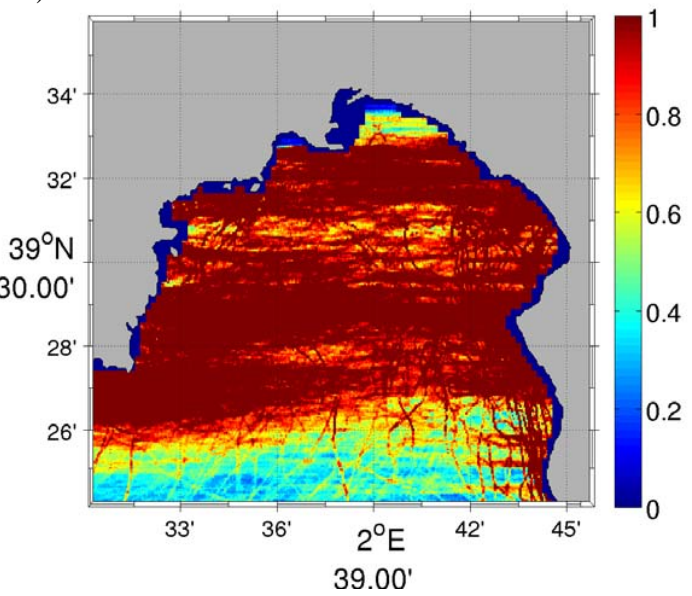

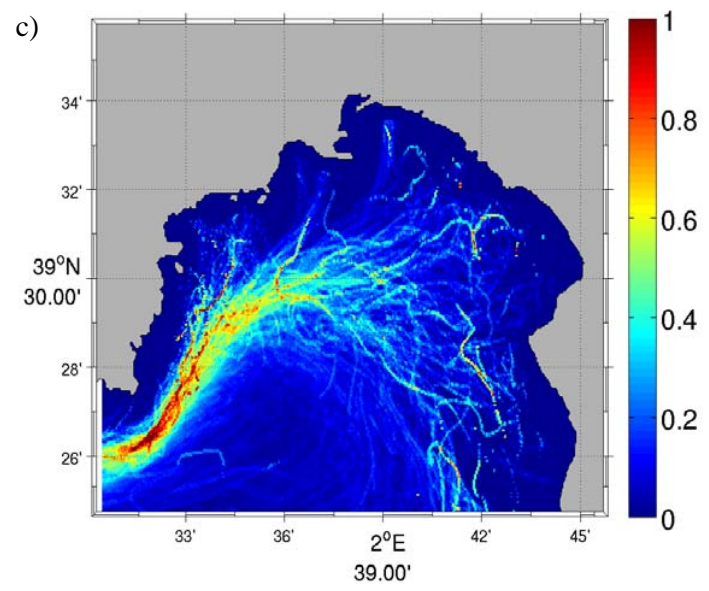

Fig. 4. Spatial distribution of the time average of 6-hourly FSLEs maps over different months and at different layers: (a) October at surface layer, (b) July at surface layer, (c) July at bottom layer.

intensity between these months, and the fact that local and remote winds are the main drivers of the bay dynamics, explains the difference in mean stirring distribution between the two months. The importance of wind will be replaced by bottom topography when going to the deep layers. The effect of the terrain topography on stirring is clear in Fig. 4c, where FSLEs are computed at the deepest layer for July. The high values of time-averaged FSLEs are located close to a region of high bathymetry gradient, which seems to act as a barrier along which the flow is stretched.

\subsection{Coastal LCSs}

The temporal averages computed in Sect. 5.1 give us a rough idea of stirring in the bay. More detailed information is obtained by looking at non-averaged quantities, which may reveal the existence of barriers to transport. Figure 5 shows the location of the high backward FSLE values (LCSs), appearing as a network of lines, computed at successive instants of time in October. These temporary structures can remain for one or more days, as happens in October, or they can appear in the same location periodically (not shown). We stress here the appearance of a clear barrier, from north to southeast, that divides the bay in two areas that correlate with the temporal average in Fig. 4a. This barrier appears in almost the same location on different days, remaining without displacing too much. To effectively see that it acts as a barrier we have considered the evolution of virtual particles released at both sides of the barrier. Red and black particles do not mix and they tend to spread along the barrier (confirming that, as expected, it is an attracting line).

In July the situation is rather different. Lines of high Lyapunov exponents (forward and backwards) are mainly oriented zonally in the bay (except close to the opening to the sea), which is also the dominant direction of motion. Thus, it does not seem that they represent hyperbolic LCSs, but rather lines of intense shear between zonally moving strips. 
a) Oct 8, 2008, at 20:00 (GMT)

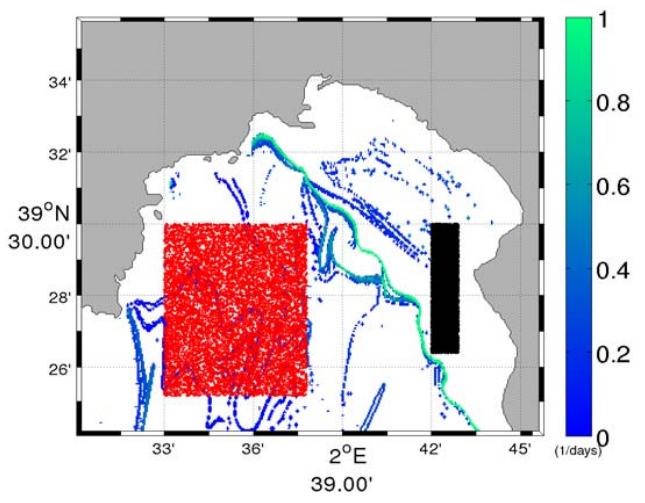

c) Oct 9, 2008, at 04:00h (GMT)

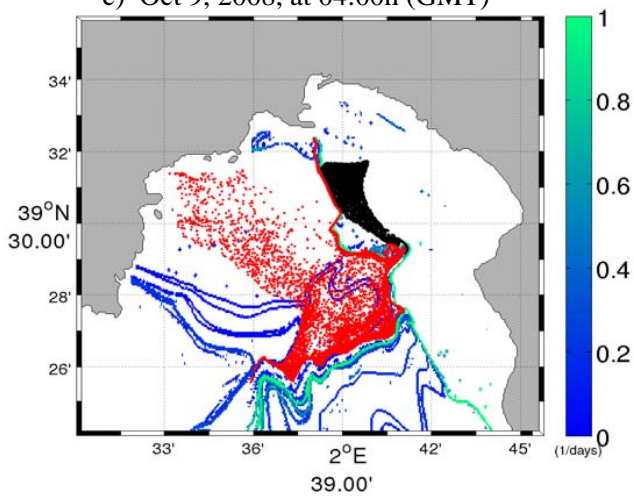

b) Oct 9, 2008 at 00:00h (GMT)

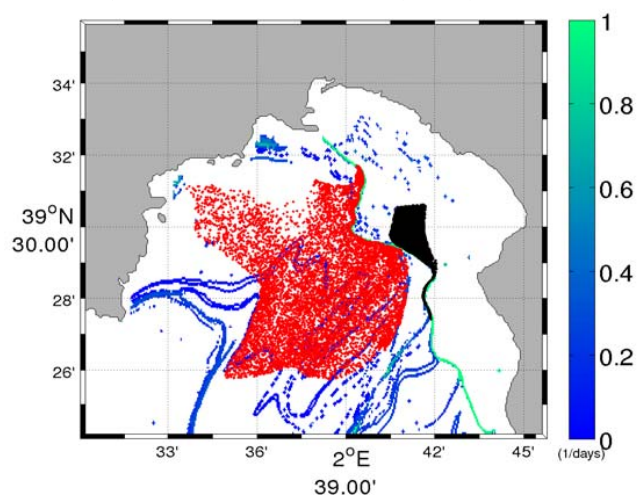

d) Oct 9, 2008 at 08:00h (GMT)

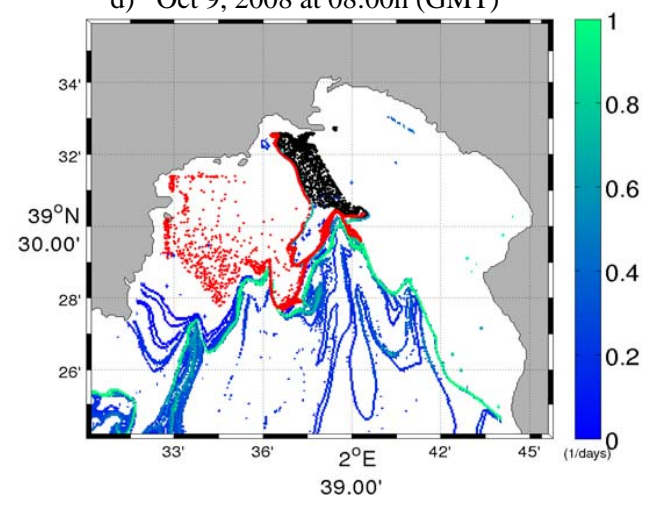

Fig. 5. Evolution of the locations of two sets of particles in the Bay of Palma during a night in October, superimposed on the spatial distributions of high values of backward FSLEs. The color bars specify FSLE values (in units of day ${ }^{-1}$ ). Zero FSLE values, displayed as white, are assigned to locations for which the particles do not attain the prescribed $\delta_{\mathrm{f}}=10 \mathrm{~km}$ separation after 5 days of integration. Note the highest values of FSLEs (green lines) act as a barrier practically dividing the bay in two parts. The two sets of particles are deployed from both sides of the barrier. (a) Initial conditions of the particles on 8 October 2008 at 20:00 GMT (Greenwich mean time); (b) 9 October 2008 at 00:00 GMT; (c) 9 October 2008 at 04:00 GMT; (d) 9 October 2008 at 08:00 GMT. Particles marked by black dots were released on the right side (northeast) of the barrier while the particles marked with red were released on the left side of the barrier.

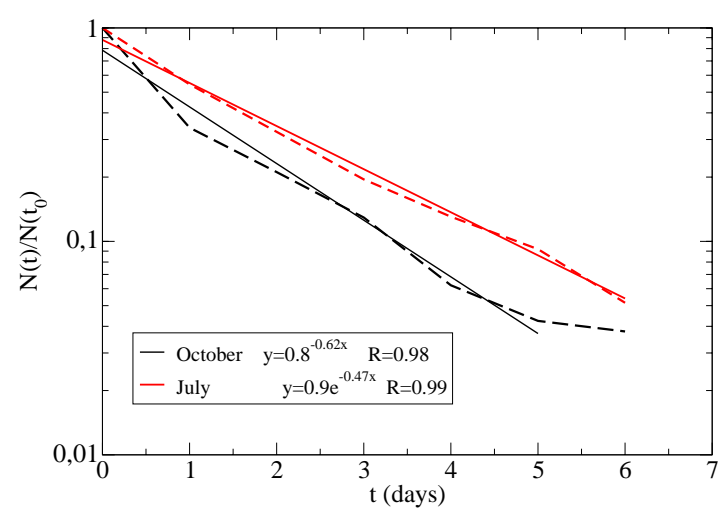

Fig. 6. Average of 15 subsequent (started at $t_{0}$ values separated $18 \mathrm{~h}$ ) estimations of $N(t)$, the number of particles remaining in the Bay of Palma at least for a lapse of time $t$ after release at $t_{0}$. Black and red lines are for surface layer in October and July respectively. Dashed lines are the measured averages, and the solid lines are the indicated exponential fits.

\subsection{Transport between the Bay of Palma and the open sea}

In this section we study the surface transport of particles in and out of the bay. To have an idea of the timescales involved in this interchange we proceed by computing the number of particles remaining in the bay, $N(t)$, averaged over different starting times (separated by $18 \mathrm{~h}$ in order to collect the information of diurnal and nocturnal signals; this gives us 15 different simulations to be averaged for each month) as a function of the integration time $t$. A particle is considered to leave the bay when crossing the red open-sea boundary in Fig. 1, so that particles landing on the coast are considered as not having escaped. Figure 6 shows the different average decays for October and July. In both cases $N(t)$ is reasonably fitted by an exponential in the considered time range, thus identifying the escape rates $\kappa=0.62$ and $0.47 \mathrm{day}^{-1}$, respectively. The corresponding escape times, given by the inverse of the escape rate, are, respectively, $\tau_{\mathrm{e}}=1.61$ and 2.12 days. The relative difference of the escape rates of July with respect to 
a)

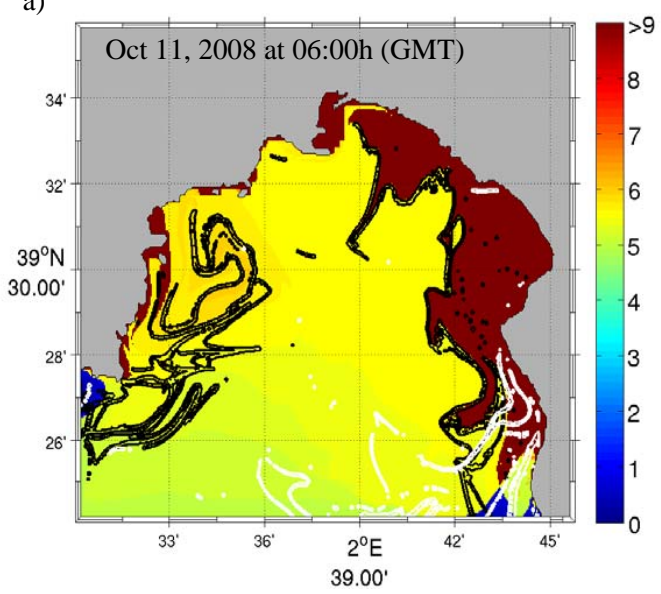

c)

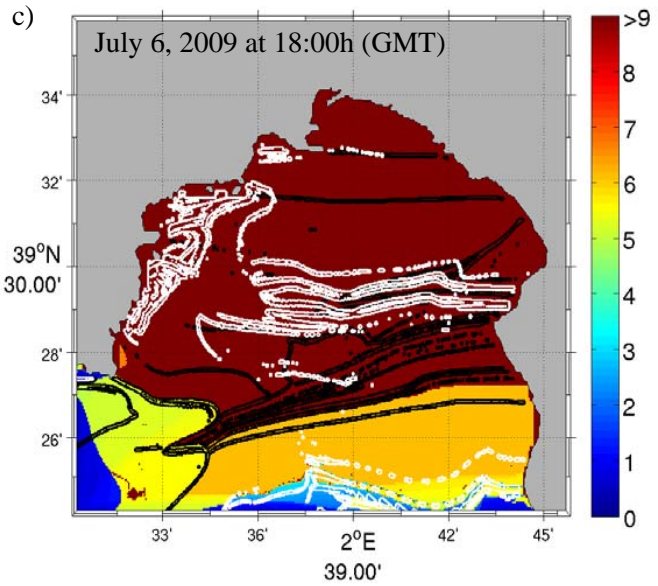

b)
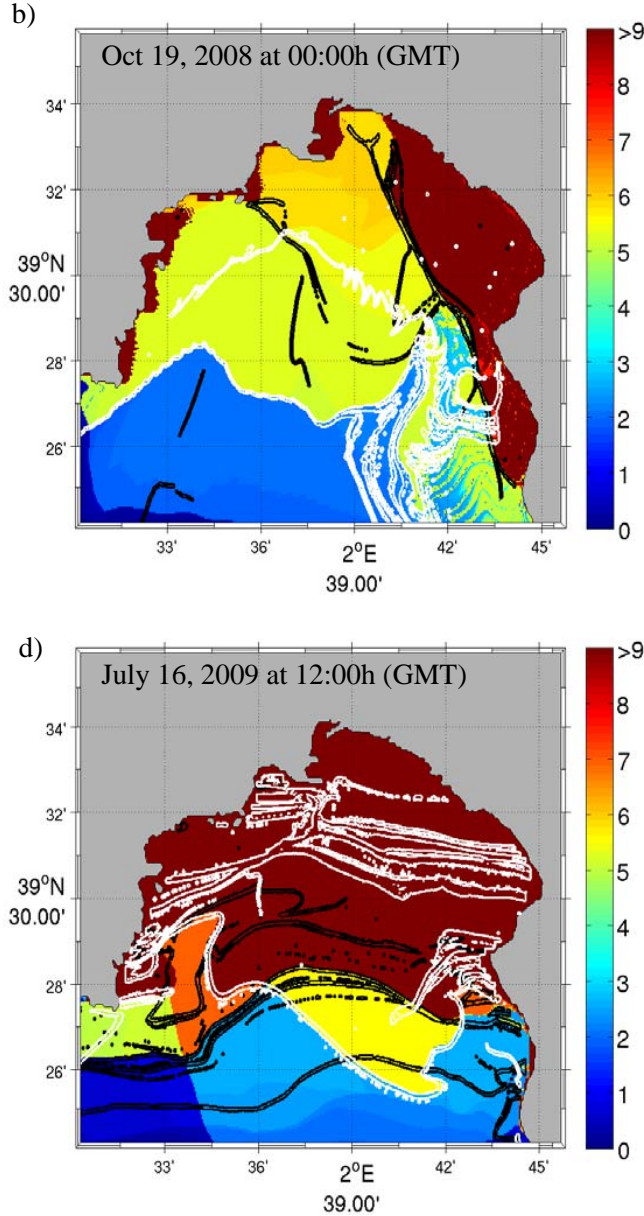

Fig. 7. Lines are the locations of top values of FSLE (greater than 0.5 day $^{-1}$ in October and greater than 1.5 day $^{-1}$ in July). Backward FSLE lines are colored in black and forward FSLEs in white. They are superimposed on spatial distributions of residence times in the Bay of Palma for different dates. The color bars give the residence times in days. (a) and (b) correspond to two different days in October, and (c) and (d) in July.

October, $\left(\kappa_{\text {October }}-\kappa_{\text {July }}\right) / \kappa_{\text {July }}$, is 0.32 . Thus the exchange of fluid particles between the bay and the open ocean is $32 \%$ more active in autumn than in summer.

Next we compute synoptic maps of the residence times. As was indicated in Sect. 3.2 the residence time of the particles throughout the study area is considered as the sum of the entry time $\left(t_{\mathrm{b}}\right)$ and the escape time $\left(t_{\mathrm{f}}\right)$. To compute $t_{\mathrm{f}}$ and $t_{\mathrm{b}}$ particles are initialized every $6 \mathrm{~h}$ in a regular grid of $75 \mathrm{~m}$ spacing and they are integrated forward and backward in time during 5 days. We consider that 5 days is a proper integration time according with the timescales associated with the coastal processes of this small bay, and also owing to the short period of the available data. In these computations we assign the maximum possible value of $t_{\mathrm{f}}$ and $t_{\mathrm{b}}$ (5 days) to the fluid particles that remain in the pre-selected area after the 5 days of integration.

In Fig. 7 we color the initial positions of particles in the bay attending to the time they transit through the bay
$\left(\mathrm{RT}=t_{\mathrm{f}}+t_{\mathrm{b}}\right)$ on different days; the initial positions of particles with short residence times are indicated in blue. Regions from where particles have longer residence time (i.e., take more time between entry and escape) are marked in $\mathrm{red} / \mathrm{brown}$.

These maps show that the spatial distribution of particle residence times can be complex and time depending, presenting different patterns at different times. A number of small structures can be observed, including thin filaments or small lobes. Comparing both months, one can see differences in the RT distributions. The most noticeable is the approximate east-west alignment of the zones of similar RT in July, which is not seen in October. Also, in October the values of particle residence times are smaller, in agreement with the global rate estimations shown before. A common feature is the southwest region with low values of residence times, because in this region there are no coastal boundaries and it is totally open to the ocean. 
a)

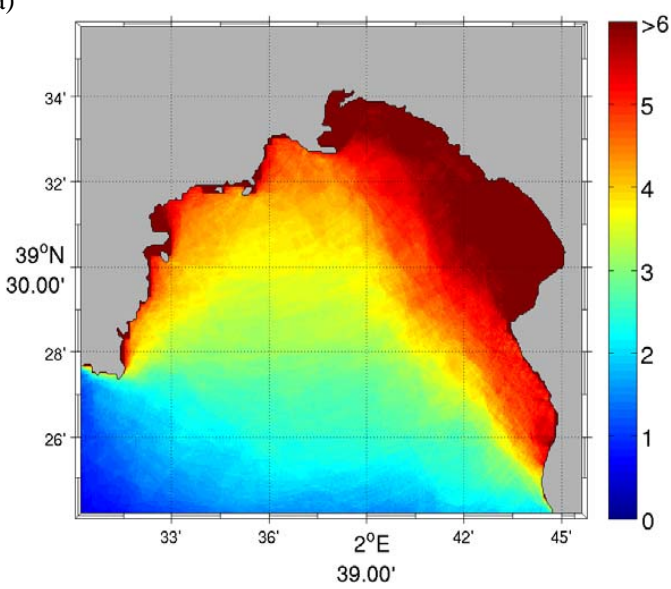

b)

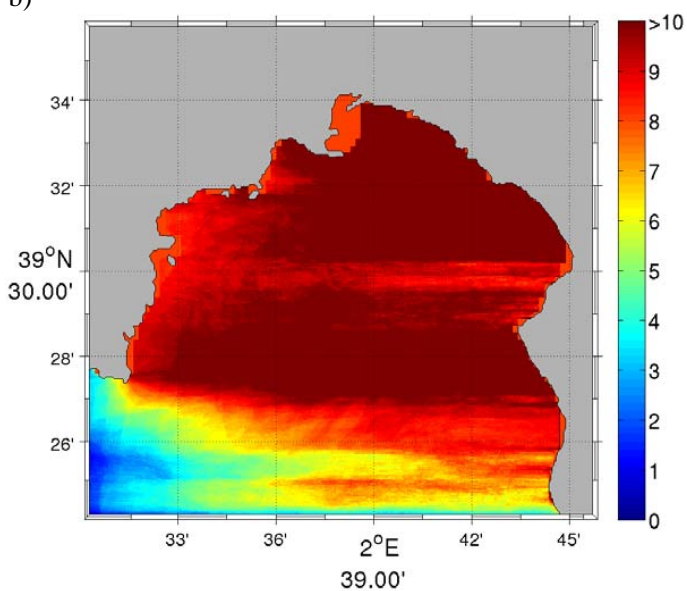

Fig. 8. Spatial distributions of time averages of 60 snapshots of 6-hourly RT values collected over 15 days in the Bay of Palma for (a) October and (b) July. The color bar units are days.

a)

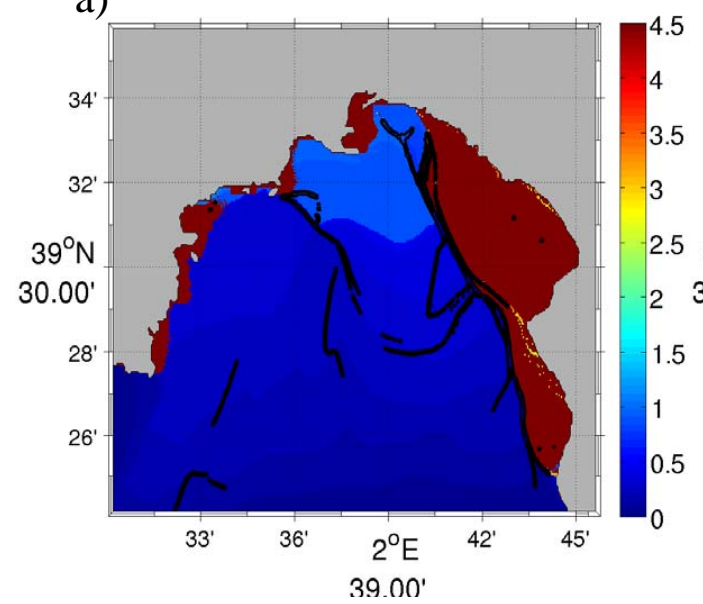

b)

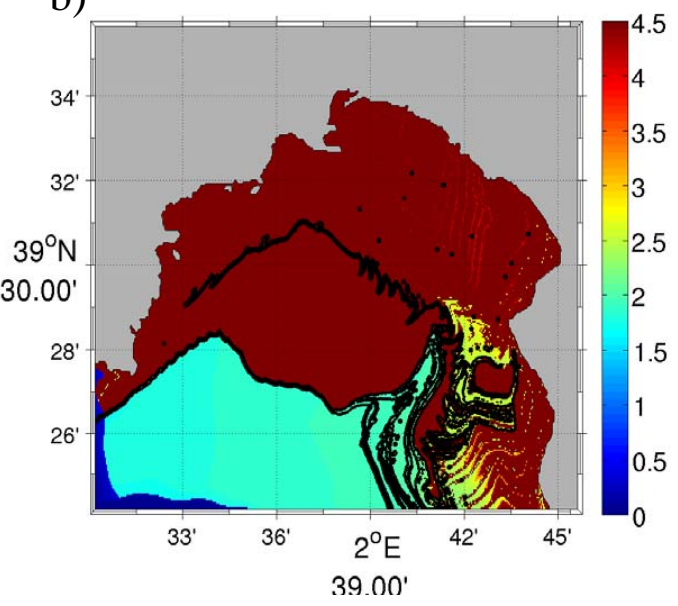

Fig. 9. Snapshots of top values of FSLE (greater than 0.5 day $^{-1}$ ) plotted over residence times. (a) is for backward integration in time, and (b) is for forward integration. Both plots correspond to 19 October at 00:00 (GMT) The color bar units are days.

In order to reveal regions with different persistent transport properties we compute time averages of the spatial distributions of residence times. We average 6-hourly snapshots of RT during 15 days (i.e., 60 snapshots) for each month. The results, plotted in Fig. 8a and b, show the common features where, in general, the low values of RT are for particles initiated close to the open ocean, specially in the southwest part, and high values are for particles started near the coast, as expected. However, on average, the residence time is larger in July than in October (3.25 days in July and 1.51 days in October) consistent with the behavior of the corresponding values of $\tau_{\mathrm{e}}$. Also, in July there is a clear boundary between the interior of the bay to the north, with large average residence times, and the open sea to the south, whereas the boundary between high and low residence times in October is well inside the bay, aligned with the Lagrangian structure identified from the FSLE analysis, as will be discussed in the next section.

Another feature observed in movies of particle trajectories (not shown) is that in October fluid particles tend to circulate mostly clockwise, while in July they are oscillating along the zonal direction (see Sect. 4). This difference, arising as discussed in Sect. 4 from the different regimes of wind forcing, is likely to be responsible for most of the different behavior between both months.

\subsection{Relation between LCSs and RTs}

We now examine the connection between regions of different residence times with LCSs. To compare RT and FSLE we have superimposed in Fig. 7 the filaments of high values of forward (white) and backward FSLE (black) values on 
a)

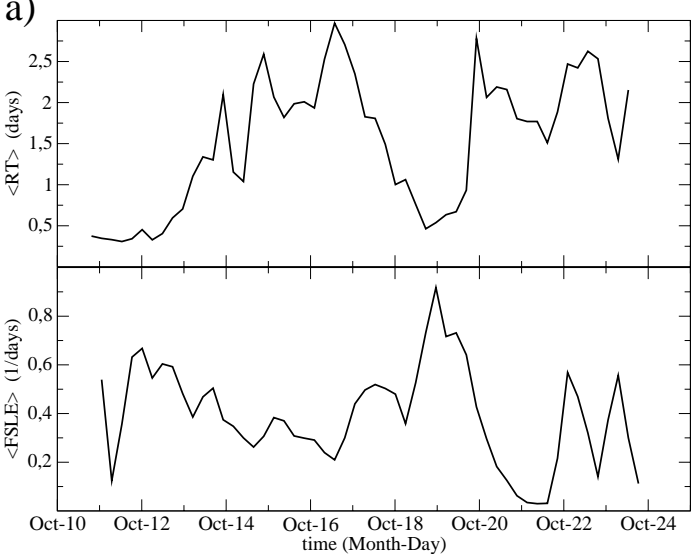

b)

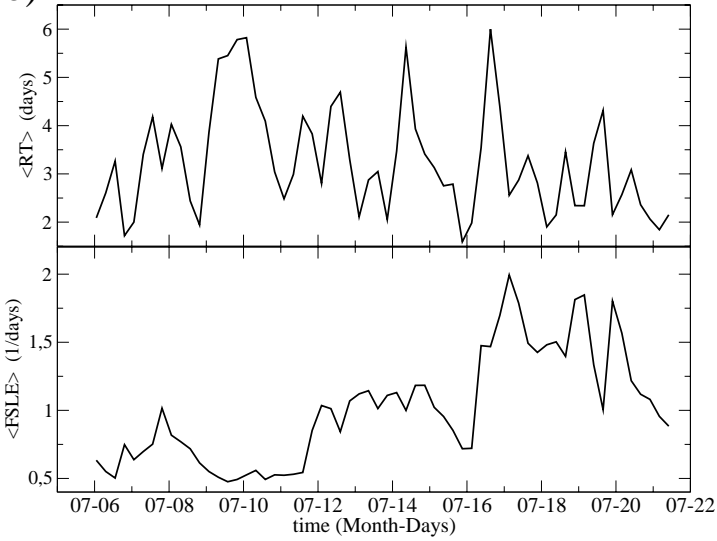

Fig. 10. (a) Time series throughout October of the spatial average of residence times (top) and spatial average of FSLE (bottom) for the surface layer of the Bay of Palma. (b) Same as (a) but for July.

the spatial distribution of residence times. The figure shows a good correspondence between many structures of RT and FSLE. Note that RT is the sum of a forward and a backward exit time, so that some of the strong gradients of RT will correspond to forward and some others to backwards LCSs. Figure 9 shows a clearer correspondence between FSLE backwards in time with entry times, and FSLE forward with escape times. At least in October, the LCSs given by high values of FSLE clearly separate regions with different values of residence times, confirming the value of the FSLE technique to identify boundaries between different flow regions and barriers to transport. There are however some lines of FSLE that are not associated to gradients of RT, and viceversa. For the first this happens mainly because we only integrate 5 days backward and 5 days forward in time, and the time assigned to the particles that do not cross the open-ocean boundary in the 5 days of integration corresponds to the maximum time integration (5 days). This makes the spatial distribution of the residence time more homogeneous. We need to integrate the trajectories longer to unveil more areas with different RT. In the same way not all abrupt changes in RT are captured by FSLE lines since we only plot the highest ridges. This illustrates that both techniques have limitations and that the complementary use of both could give a rather complete overview of the geometric structure of flow in marine areas. Pattantyús-Ábrahám et al. (2008) studied the relation between residence time and FSLE for a wind-forced hydrodynamical model of a shallow lake. They found that areas with long residence time visualize the stable manifolds of the so-called chaotic saddle, a structure controlling the escape properties at long times. In our case, our integrations are restricted to times too short to characterize long-time chaotic behavior, but still there is a good correspondence between the FSLE structures characterizing attracting or repelling trajectories, and escape or residence times.

Figure 8a shows a time average over October of the spatial distribution of RT, to be compared with the corresponding average figure (Fig. 4a) for FSLE. It is evident that the region in the northeast side of the bay with high values of RT is separated from the rest by a region of high values of FSLE. This can be explained by the presence of persistent barriers that do not allow particles to escape from the northeast side of the bay, and thus separating the bay in regions with different residence times. In July the situation is different, because the spatial distribution of FSLE (Fig. 4b) and RT (Fig. 8b) is almost homogeneous, with higher values over the whole area of the bay, and lower values in the small region bordering the open ocean. This indicates that the instantaneous configurations of high FSLE lines (Fig. 7) are not persistent, and that there is only a persistent large difference between the interior of the bay and its opening to the ocean. The predominantly zonal direction of particle motion in the bay is consistent with the orientation of the boundaries between areas of different RTs in July.

\subsection{Variability of RT and FSLE}

The differences of residence times and FSLEs in the two considered months indicate that the dynamics of the flow is qualitatively different, as anticipated by the different wind regimes that are the main drivers of the bay. Now we analyze the time evolution of their spatial averages.

Figure 10a and $\mathrm{b}$ show the time series of the spatial mean of residence times (top panel) and backward FSLE (bottom panel) for October and July, respectively.

A comparison between time evolution of spatial averages of the RTs for the different months confirms, again, that particles tend to stay longer times in the bay in July than in October. The values of RT vary approximately from 0.25 to 3 days in October (Fig. 10a, top), and from 2 to 6 days in July (Fig. 10b, top). The same happens with FSLE, higher values correspond to July and lower ones to October. Diurnal fluctuations, likely related to the effect of the sea breeze, are evident in RT and FSLE for both months. In October there are some large fluctuations of low frequency in RT, probably induced by the variability of remote forcing winds. On 
a)

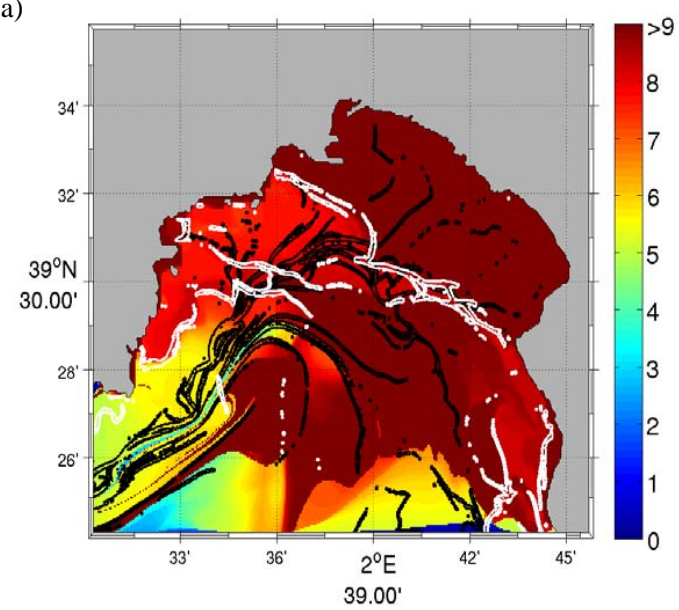

b)

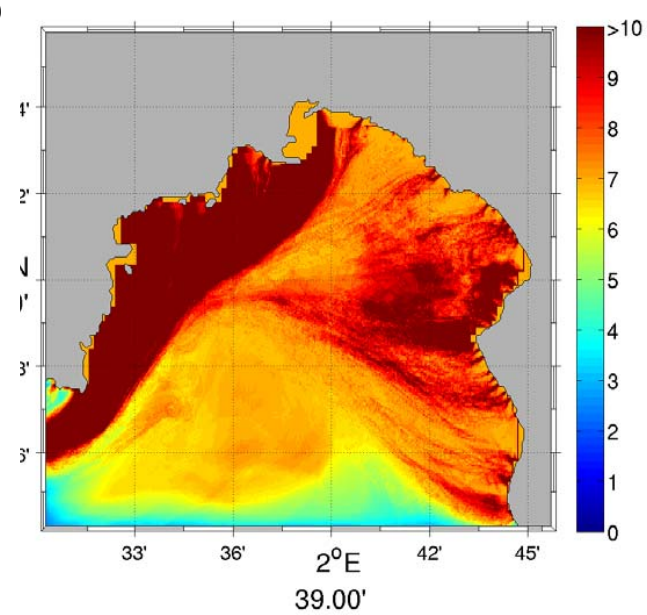

Fig. 11. (a) Snapshot of spatial distributions of residence times at the bottom layer in the Bay of Palma corresponding to 17 July 2009 at 18:00 (GMT). Lines are the locations of top values of FSLE (greater than 0.3 day $^{-1}$ ). Backward FSLE lines are colored in black and forward FSLEs in white. (b) Spatial distribution of time average of 60 snapshots from 6-hourly maps of RT collected over 15 days in July at the bottom layer.

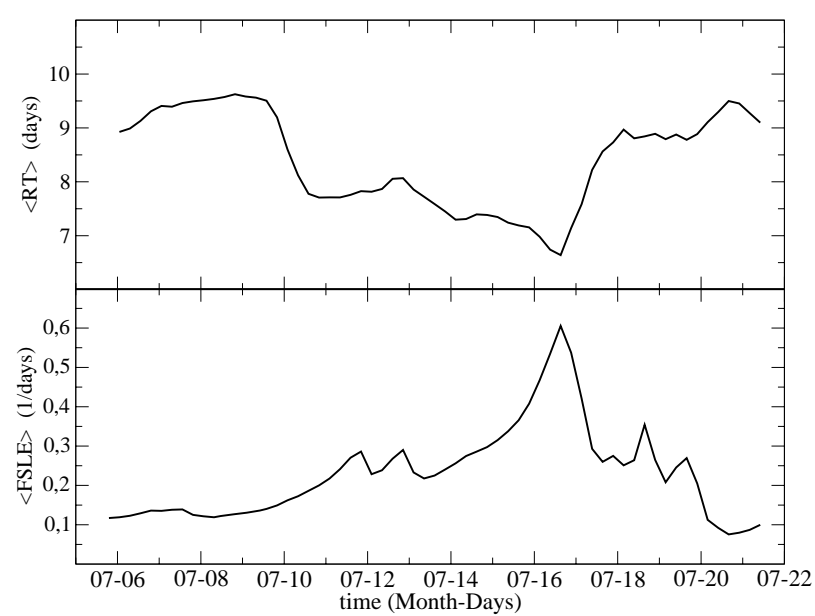

Fig. 12. Time series throughout July of (top) spatial average of residence times and (bottom) spatial average of FSLE computed for the bottom layer.

the other hand, during October, minima of RT correspond to maxima of FSLE, and maxima of RT correspond to minima of FSLE. In July, the relationship between FSLE and RT is looser and only observed in the high-frequency fluctuations. To be more quantitative, the Pearson correlation coefficient between RT and FSLE time series is -0.526 in October, but just -0.223 in July. This difference in behavior probably arises from the fact that high values of FSLE determine clear and well-defined barriers to transport only in the case of October (see Sects. 5.3 and 5.4). In July, lines of high FSLE remain nearly zonal and parallel to dominant particle direction of motion. Thus, as commented in Sect. 5.2, they probably represent regions of high zonal shear everywhere in the bay. Their high or low values indicate large or small differences in east-west velocities but by themselves they do not imply stronger or weaker escape towards the south.

\subsection{Transport at the bottom layer}

In this subsection we compare the main Lagrangian characteristics at the bottom layer, not driven directly by wind, with those at the surface. In Fig. 11a we show an instantaneous map of the residence times in the bottom layer for one day in July, overlayed with lines of high FSLE values. Again, the spatial distribution is inhomogeneous, and we find high values of RT over all the bay except very close to the ocean. The correlation of RT values with FSLE lines is weaker than in the upper layer, but still we see that the relatively lower values of RT in the western part of the bay on that particular day appear bounded by backward FSLE lines, indicating a temporal escape route of particles in that region towards the southwest. The spatial distribution of the time average of RT plotted in Fig. 11b shows that the highest average values of RT are concentrated in the northwestern region of the bay. Figure $4 \mathrm{c}$ displays high values of FSLE located precisely in the same region where the RT qualitatively changes to high values. This suggests the presence of persistent barriers that separate this southeastern region from the rest in this bottom layer. The formation of these persistent LCSs is associated to the gradient of the bathymetry (see Fig. 1).

The time evolution of the spatial average of RT and FSLE are plotted in the top and bottom panels in Fig. 12, respectively. Contrarily to the surface, in the bottom layer the diurnal fluctuations in the time series of RT disappear, showing that the flow at this depth is not directly influenced by breeze. 
The RT values are larger than in the surface, and therefore the interchange between the ocean and the bay is less intense at bottom layers. This is a consequence of the slowness of the flow produced by the absence of direct wind forcing at the deepest levels. There is a strong negative correlation $(r=-0.803)$ between stirring and residence times: when the flow is more dispersive the particles transit less time over the bay, so that the maxima of RT corresponds to the minima of FSLE and vice versa.

\section{Conclusions}

Properties of coastal transport in the Bay of Palma, which is a small semi-enclosed region of the island of Mallorca, were studied in a Lagrangian framework, by using model velocity data at high resolution. We have applied two complementary Lagrangian methods (FSLEs and RT) to analyze the small scales of these coastal currents. LCSs have been detected as high ridges of FSLE, and virtual experiments with particle trajectories have shown that these structures really act as barriers in most cases, organizing the coastal flow. Global and average aspects of the transport in different seasonal months show that, in the period studied, in autumn there is more exchange between the bay and the open ocean than in summer. This arises from the different wind regimes in both months, which during July induce a flow that restricts motion of the coastal marine surface to the zonal direction, preventing the flow to enter or escape toward the open ocean. The transport of particles at the deepest layer is less active than at the surface and not directly driven by wind, but influenced by the bottom topography. Regions with different values of RT are generally separated by ridges of FSLE, proving the fact that FSLE separates regions of qualitatively different dynamics also in small coastal regions. Thus, we think that these Lagrangian quantities can be used as key variables able to determine the dynamics and health of other bays or estuaries, particularly in relation with human activities. Future improvements include the adaptation of these methods to three-dimensional spaces and capture three-dimensional effects, such as upwelling and downwelling in coastal areas, and analyzing longer periods of time.

Acknowledgements. I. Hernández-Carrasco, C. López and E. Hernández-García acknowledge support from MICINN and FEDER through projects FISICOS (FIS2007-60327), INTENSE@COSYP (FIS2012-30634), and ESCOLA (CTM201239025-C02-01). A. Orfila acknowledges financial support from MICINN and EU-Med Programme through projects BUS2 (CGL2011-22964) and TOSCA (2GMED-09-425). We acknowledge the ICMAT Severo Ochoa project (SEV-2011-0087) for funding the publication charges of this article.

Edited by: A. Turiel

Reviewed by: two anonymous referees

\section{References}

Antonov, J. I., Locarnini, R. A., Boyer, T. P., Mishonov, A. V., and Garcia, H. E.: World Ocean Atlas 2005, Volume 2: Salinity. S. Levitus, Ed. NOAA Atlas NESDIS 62, US Government Printing Office, Washington, DC, 2006.

Aurell, E., Boffetta, G., Crisanti, A., Paladin, G., and Vulpiani, A.: Predictability in the large: an extension of the Lyapunov exponent, J. Phys. A, 30, 1-26, 1997.

Boffetta, G., Lacorata, G., Redaelli, G., and Vulpiani, A.: Detecting barriers to transport: a review of different techniques, Physica D, 159, 58-70, 2001.

Buffoni, G., Cappelletti, A., and Cupini, E.: Advection-diffusion processes and residence times in semi-enclosed marine basins, Int. J. Numer. Methods Fluids, 22, 1-23, 1996.

Buffoni, G., Falco, P., Griffa, A., and Zambianchi, E.: Dispersion processes and residence times in a semi-enclosed basin with recirculating gyres: an application to the Tyrrhenian Sea, J. Geophys. Res., 102, 18699-18713, 1997.

Calil, P. and Richards, K.: Transient upwelling hot spots in the oligotrophic North Pacific, J. Geophys. Res, 115, C02003, doi:10.1029/2009JC005360, 2010.

Cencini, M., Cecconi, F., and Vulpiani, A.: Chaos: From simple models to complex systems, Series on Advances in Statistical Mechanics, World Scientific, Singapore, 2010.

Dobricic, S., Pinardi, N., Adani, M., Tonani, M., Fratianni, C., Bonazzi, A., and Fernandez, V.: Daily oceanographic analyses by Mediterranean Forecasting System at the basin scale, Ocean Sci., 3, 149-157, doi:10.5194/os-3-149-2007, 2007.

d'Ovidio, F., Fernández, V., Hernández-García, E., and López, C.: Mixing structures in the Mediterranean sea from FiniteSize Lyapunov Exponents, Geophys. Res. Lett., 31, L17203, doi:10.1029/2004GL020328, 2004.

d'Ovidio, F., Isern-Fontanet, J., López, C., Hernández-García, E., and García-Ladona, E.: Comparison between Eulerian diagnostics and Finite-Size Lyapunov Exponents computed from Altimetry in the Algerian basin, Deep-Sea Res. I, 56, 15-31, 2009.

Falco, P., Griffa, A., and Poulain, P. M.: Transport properties in the Adriatic Sea as deduced from drifter data, J. Phys. Oceanogr., 30, 2055-2071, 2000.

Fiorentino, L. A., Olascoaga, M. J., Reniers, A., Feng, Z., BeronVera, F., and MacMahan, J. H.: Using Lagrangian Coherent Structures to understand coastal water quality, Cont. Shelf Res., 47, 145-149, 2012.

Galan, A., Orfila, A., Simarro, G., Hernández-Carrasco, I., and López, C.: Wave mixing rise inferred from Lyapunov exponents, Environ. Fluid Mech., 12, 291-300, 2012.

Gildor, H., Fredj, E., Steinbuck, J., and Monismith, S.: Evidence for Submesoscale Barriers to Horizontal Mixing in the Ocean from Current Meauserements and Aerial Photographs, J. Phys. Oceanogr., 39, 1975-1983, 2009.

Haidvogel, D., Blanton, J., Kindle, J., and Lynch, D.: Coastal Ocean Modeling: Processes and Real-Time Systems, Oceanography, 13, 35-46, 2000.

Haller, G.: A variational theory of hyperbolic Lagrangian Coherent Structures, Physica D, 240, 574-598, 2011. Erratum and addendum: Physica D 241, 439-441, 2012.

Haller, G. and Beron-Vera, F. J.: Geodesic theory of transport barriers in two-dimensional flows, Physica D: Nonlinear Phenomena, 241, 1680-1702, 2012. 
Haller, G. and Yuan, G.: Lagrangian coherent structures and mixing in two-dimensional turbulence, Physica D, 147, 352-370, 2000.

Haza, A. C., Özgökmen, T. M., Griffa, A., Molcard, A., Poulain, P.M., and Peggion, G.: Transport properties in small-scale coastal flows: relative dispersion from VHF radar measurements in the Gulf of La Spezia, Ocean Dynam., 60, 861-882, 2010.

Hernández-Carrasco, I., López, C., Hernández-García, E., and Turiel, A.: How reliable are finite-size Lyapunov exponents for the assesment of ocean dynamics?, Ocean Model., 36, 208-218, 2011.

Huhn, F., von Kameke, A., Allen-Perkins, S., Montero, P., Venancio, A., and Pérez-Muñuzuri, V.: Horizontal Lagrangian transport in a tidal-driven estuary - Transport barriers attached to prominent coastal boundaries, Cont. Shelf Res., 39-40, 1-13, 2012.

Jordi, A., Basterretxea, G., and Wang, D.-P.: Evidence of sediment resuspension by island trapped waves, Geophys. Res. Lett., 36, doi:10.1029/2009GL040055, 2009.

Jordi, A., Basterretxea, G., and Wang, D.-P.: Local versus remote wind effects on the coastal circulation of a microtidal bay in the Mediterranean Sea, J. Mar. Syst., 88, 312-322, 2011.

Joseph, B. and Legras, B.: Relation between Kinematic Boundaries, Stirring, and Barriers for the Antartic Polar Vortex, J. Atmos. Sci., 59, 1198-1212, 2002.

Koh, T. and Legras, B.: Hyperbolic lines and the stratospheric Polar vortex, Chaos, 12, 382-394, 2002.

Lai, Y. and Tel, T.: Transient Chaos: Complex Dynamics on FiniteTime Scales, Springer, 2011.

Lehan, Y., d'Ovidio, F., Lévy, M., and Heyfetz, E.: Stirring of the Northeast Atlantic spring bloom: A Lagrangian analysis based on multisatellite data, J. Geophys. Res., 112, C08005, doi:10.1029/2006JC003927, 2007.

Lekien, F., Coulliette, C., Mariano, A. J., Ryan, E. H., Shay, L. K., Haller, G., and Marsden, J.: Pollution release tied to invariant manifolds: A Case study for the coast of Florida, Physica D, 210, 1-20, 2005.

Lipphardt, B., Jr., Small, D., Kirwan, A., Jr., Wiggins, S., Ide, K., Grosch, C., and Paduan, J.: Synoptic Lagrangian maps: Aplication to surface transport in Monterey Bay, J. Mar. Res., 64, 221247, 2006.

Locarnini, R. A., Mishonov, A. V., Antonov, J. I., Boyer, T. P., and Garcia, H. E.: World Ocean Atlas 2005, Volume 1: Temperature. S. Levitus, Ed. NOAA Atlas NESDIS 61, US Government Printing Office, Washington, DC, 2006.

Mancho, A. M., Small, D., and Wiggins, S.: A tutorial on dynamical systems concepts applied to Lagrangian transport in oceanic flows defined as finite time data sets: Theoretical and computational issues, Physics Reports, 437, 55-124, 2006.

Mendoza, C. and Mancho, A. M.: Hidden Geometry of Ocean Flows, Phys. Rev. Lett., 105, 038501, doi:10.1103/PhysRevLett.105.038501, 2010.

Mezić, I., Loire, S., Vladimir, A., Fonoberov, A., and Hogan, P.: A New Mixing Diagnostic and Gulf Oil Spill Movement, Science, 330, 486-489, 2010.
Nencioli, F., d'Ovidio, F., Doglioli, A., and Petrenko, A.: Surface coastal circulation patterns by in-situ detection of Lagrangian Coherent Structures, Geophys. Res. Lett., 38, L17604, doi:10.1029/2011GL048815, 2011.

Oddo, P., Adani, M., Pinardi, N., Fratianni, C., Tonani, M., and Pettenuzzo, D.: A nested Atlantic-Mediterranean Sea general circulation model for operational forecasting, Ocean Sci., 5, 461-473, doi:10.5194/os-5-461-2009, 2009.

Ohlmann, J. C., LaCasce, J. H., Washburn, L., Mariano, A. J., and Emery, B.: Relative dispersion observations and trajectory modeling in the Santa Barbara Channel, J. Geophys. Res., 117, C05040, doi:10.1029/2011JC007810, 2012.

Orfila, A., Jordi, A., Basterretxea, G., Vizoso, G., Marba, N., Duarte, C., Werner, F., and Tintoré, J.: Residence time and Posidonia oceanica in Cabrera Archipelago National Park, Spain, Cont. Shelf Res., 25, 1339-1352, 2005.

Pattantyús-Ábrahám, M., Tél, T., Krámer, T., and Józsa, J.: Mixing properties of a shallow basin due to wind-induced chaotic flow, Adv. Water Res., 31, 525-534, 2008.

Ramis, C. and Alonso, S.: Sea Breeze convergence line in Mallorca, A satellite observation, Weather, 43, 288-293, 1988.

Ramis, C. and Romero, R.: A first numerical simulation of the development and structure of the sea breeze on the Island of Mallorca, Ann. Geophys., 13, 981-994, doi:10.1007/s00585-9950981-3, 1995.

Rypina, I. I., Scott, S. E., Pratt, L. J., and Brown, M. G.: Investigating the connection between complexity of isolated trajectories and Lagrangian coherent structures, Nonlin. Processes Geophys., 18, 977-987, doi:10.5194/npg-18-977-2011, 2011.

Shadden, S. C., Lekien, F., and Marsden, J. E.: Definition and properties of Lagrangian coherent structures from finite-time Lyapunov exponents in two dimensional aperiodic flows, Physica D, 212, 271-304, 2005.

Shadden, S. C., Lekien, F., Paduan, J. D., Chavez, F. P., and Marsden, J. E.: The correlation between surface drifters and coherent structures based on high-frequency radar data in Monterey Bay, Deep Sea Research Part II: Topical Studies in Oceanography, 56, 161-172, 2009.

Song, Y. and Haidvogel, D.: A Semi-implict Ocean Circulation Model Using a Generalized Topography-Following Coordinate System, J. Comput. Phys., 115, 228-244, 1994.

Tél, T. and Gruiz, M.: Chaotic dynamics: An introduction based on classical mechanics, Cambridge Univ. Press, Cambridge, 2006.

Tew Kai, E., Rossi, V., Sudre, J., Weimerskirch, H., López, C., Hernández-García, E., Marsac, F., and Garçon, V.: Top marine predators track Lagrangian coherent structures, Proceedings of the National Academy of Sciencies of the USA, 106, 8245-8250, 2009.

Tudurí, E. and Ramis, C.: The environments of significant convective events in the western Mediterranean, Weather Forecast., 12, 294-306, 1997. 